\title{
Impact of Wind Farms of DFIG Type on Power System Transient Stability
}

\author{
Libao Shi ${ }^{1}$, Shiqiang Dai ${ }^{1}$, Liangzhong Yao $^{2}$, Yixin $\mathrm{Ni}^{1}$, Masoud Bazargan ${ }^{2}$ \\ ${ }^{1}$ National Key Laboratory of Power System in Shenzhen, Graduate school at Shenzhen, Tsinghua University, Shenzhen, China; \\ ${ }^{2}$ AREVA T\&D Technology Centre, Stafford, UK. \\ Email: shilb@sz.tsinghua.edu.cn, liangzhong.yao@areva-td.com
}

Received May 23 ${ }^{\text {rd }}, 2010$; revised June $22^{\text {nd }}, 2010$; accepted July $2^{\text {nd }}, 2010$

\begin{abstract}
The impact of large-scale grid-connected wind farms of Doubly-fed Induction Generator (DFIG) type on power system transient stability is elaborately discussed in this paper. In accordance with an equivalent generator/converter model, the comprehensive numerical simulations with multiple wind farms of DFIG type involved are carried out to reveal the impact of wind farm on dynamic behavior of existing interconnected power system. Different load models involving nonlinear load model and induction motor model are considered during simulations. Finally, some preliminary conclusions are summarized and discussed.
\end{abstract}

Keywords: Transient Stability, DFIG, Multiple Wind Farms, Wind Farm Integration, Load Model

\section{Introduction}

In recent years, the increasing concerns to the environmental issues and the limited availability of conventional fossil fuels lead to rapid research and development for more sustainable and alternative electrical sources. Wind energy, as one of the most prominent renewable energy sources, is gaining increasing significance throughout the world. The currently worldwide installed capacity of gridconnected wind generators grows rapidly, and particularly in China, the installed capacity doubles every year since 2004. The vast majority of presently installed wind turbines are based on the following three main types of electromechanical conversion systems. The $1^{\text {st }}$ type is normally referred to as a constant-speed or fixed-speed turbine. The $2^{\text {nd }}$ type uses a DFIG instead of a SCIG as a variable-speed wind turbine. The $3^{\text {rd }}$ type is called a direct-drive synchronous generator different from the DFIG. The fixed-speed wind turbines equipped with an induction generator (squirrel cage or wound rotor) have ever been widely used because of the advantage of being simple, robust, reliable and well-proven. Also the cost of its electrical parts is low. However, the disadvantages of uncontrollable reactive power consumption, mechanical stress and limited power quality control lead to little con-

\footnotetext{
*This work has also been supported in part by the National Natural Science Foundation of China (50977051), the Research Project of Science and Technology from Shenzhen Government of China (JC200903 180528A)
}

tributions on improving system dynamic behavior. Especially, owing to its fixed speed operation, all fluctuations in the wind speed are further transmitted as fluctuations in the mechanical torque and then as fluctuations in the electrical power on the grid. With rapid development in power electronic converters recently, an alternative, the variable-speed wind turbine, has appeared during the past few years and has become the dominant type among the new installed wind turbines. It should be pointed out that the Doubly-fed Induction Generator (DFIG) equipped wind turbine is currently the most popular one due to its capability of controlling reactive power, high energy efficiency, and the fact that the converter rating of appropriately $20 \%-30 \%$ of the total machine power is needed [1,2]. Accordingly, modeling of wind turbine with DFIG will be the highlight to be issued in this paper.

It is known that the electrical characteristics of DFIG determined by the converter are quite different from the conventional synchronous generators. Power system engineers will have to confront a series of challenges imposed by integration of large wind power with the existing power systems. One of important issues engineers have to face is the impact of wind power penetration on the dynamic behavior, e.g. the transient stability, of an existing interconnected large-scale power system.

So far, much literature related to transient stability analysis of power system with high penetration of gridconnected wind farms of DFIG type have been studied 
in [3-9]. Vicatos, Tegopoulos [3] and Senjyu et al. [4] discussed the transient characteristics of wind farm during the three-phase short circuit condition. Jenkins et al. [5] and Shi et al. [6] studied dynamic mathematical model of DFIG suitable for transient stability analysis. Muyeen et al. [7] presented detailed analysis of windmill mechanical drive train models for transient stability analysis of wind power generation system. They pointed out that at least two-mass shaft model was needed in the transient stability analysis of wind turbine generation system. Gautam et al. [8] and Weise et al. [9] examined the impact of high wind generation penetration on transient stability and small signal stability of an existing power system. Shi et al. [10] studied the influence of DFIG type wind farms on transient stability of the power system, while comparing with the synchronous generators connected to the power system at the same point.

In the published literature, some of them mainly focused on the electromagnetic transient models $[3,4]$ unsuitable for transient stability analysis of large-scale power system. As for the applications of the electromechanical transient model of DFIG in an existing power system [8-10], some studied test systems were too simple and the impact of dynamic load model was neglected during simulations. Besides, only single wind farm $[8,10]$ was introduced to conduct the transient stabiity analysis. In a nutshell, the transient stability analysis of power system with high penetration of wind farms of DFIG type needs to be elaborately explored and exploited further.

In this paper, the detail numerical simulations on the IEEE 10-generator-39-bus New England test system as benchmark are carried out to discuss the influence and interaction of DFIG type wind farms on power system transient stability. Multiple wind farms are introduced into the existing test system during analysis by replacing the existing synchronous generators and integrating into the specific buses. Different load models including the nonlinear and dynamic motor models are also considered. Finally, some meaningful and preliminary conclusions are given in this paper.

The rest of this paper is organized as follows. Section 2 briefly introduces the mathematical models of DFIG and converters. In Section 3, the detail case studies focusing on the impacts of grid-connected wind farms on an existing test system are carried out. Finally the conclusions and discussions are summarized in Section 4.

\section{Modeling of DFIG and Converters}

In the following discussions, the whole wind farm is modeled as an aggregated wind park model by one equivalent wind generator [1,2]. A general scheme of a DFIG including the static converters and controllers is depicted in Figure 1. Two converters are connected be- tween the rotor and grid, following a back-to-back scheme with a dc intermediate link.

In the modeling of turbine rotor, there are a lot of different ways to represent the wind turbine [1]. In our studies, a kind of functions approximation method [11] is used to simulate the wind turbine aerodynamic model. Furthermore, we assume that the wind speed can be kept as constant during the transient stability simulation. The pitch angle control strategy is also considered, which is implemented by a kind of PI controller [11], to limit the aerodynamic efficiency of the rotor.

For the modeling of DFIG, a two-mass shaft model $[10,11]$ is employed to represent the drive train. The interface between the wind turbine generator and the network is simplified as an algebraic, controlled-current source $[10,11]$ which computes the required injected current into the network in response to the flux and active current commands from the converter model. For a given time step, the model holds the in-phase (active power) component of current constant and holds constant q-axis voltage behind the sub-transient reactance (X").

The model of the frequency converter system is generally represented with the rotor-side converter, grid-side converter, the dc link and the corresponding converter control. The modeling of rotor-side converter from [11] is employed to implement the decoupled control for stator active and reactive powers. The corresponding control block diagrams are shown in Figure 2 and Figure 3.

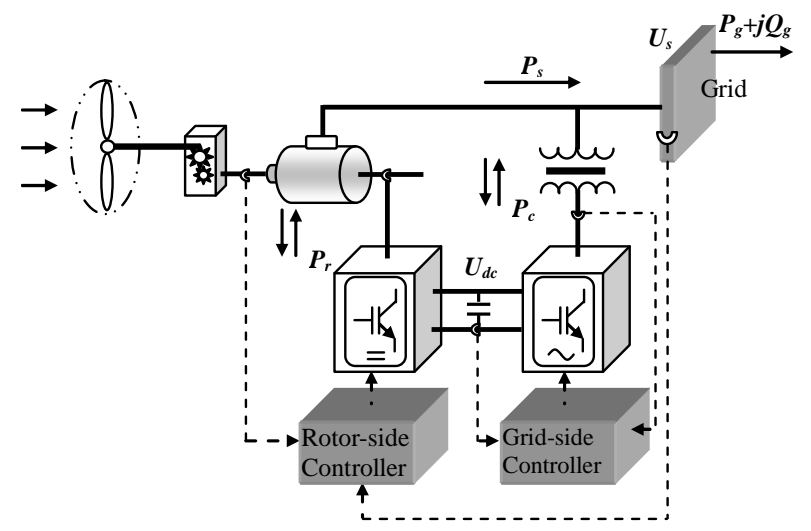

Figure 1. General scheme of a DFIG including converters and controllers

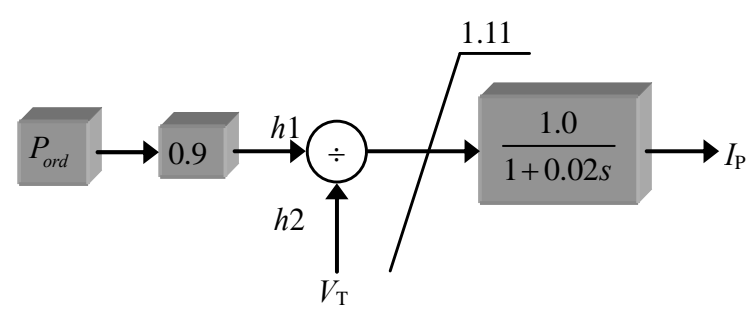

Figure 2. Block diagram for active power control 


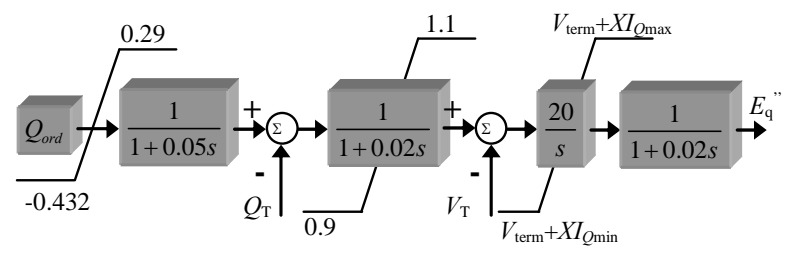

Figure 3. Block diagram for reactive power control

Where, $P_{\text {ord }}$ is the active power demand determined by wind turbine; $V_{\mathrm{T}}$ is terminal voltage considering measurement block; $Q_{\text {ord }}$ is reactive power demand determined by the supervisory VAR controller; $E_{\mathrm{q}}$ " and $I_{\mathrm{p}}$ are the flux and active current commands from the converter model [11]. In our studies, the grid-side converter is assumed to be ideal, and the dc link voltage between the converters is kept as constant.

\section{Case Study}

\subsection{Transient Stability Evaluation Index}

In our work, the following two indices [12,13] are used to evaluate the impact of grid-connected wind farms of DFIG type on the transient stability of the test system.

1) Power angle based stability index [13]

This index is defined as follows for each island in the system:

$$
\eta=\frac{360-\delta_{\max }}{360+\delta_{\max }} \times 100 \quad-100<\eta<100
$$

where $\delta_{\max }$ is the maximum angle separation of any two generators in the island at the same time in the post-fault response. The transient stability index for the system is taken from the smallest index among all islands. Thus, $\eta$ $>0$ and $\eta \leq 0$ correspond to stable and unstable conditions respectively. This index is directly proportional to system angle separation. Hence it provides a good indication of how severe a test system is following a contingency.

2) Critical clearance time (CCT) of faults [13]

The critical clearance time of a fault is generally considered as the best measurement of severity of a contingency and thus widely used for ranking contingencies in accordance with their severity. In our studies, the CCT is employed as a transient stability index to evaluate the test system. CCT is defined as the longest allowed fault clearance time without losing stability. This is obtained, using a binary search method [13], within a specified fault clearance range with a set threshold. If the change of the system operation can increase CCT, it is considered that such change is favorable to improve power system transient stability.

\subsection{Application Example}

The IEEE 10-generator-39-bus New England test system shown in Figure 4 is employed to conduct the transient stability simulation. Detailed parameters of this system can be found in [14]. All simulations are implemented on the DSA-TSAT/UDM ${ }^{\mathrm{TM}}$ [12] simulation environment, developed by Powertech Labs Inc., Canada.

\subsubsection{Multiple Wind Farms Replacing Synchronous Generators}

In order to make more sense to replace the synchronous generators with wind farms for the power system transient stability analysis, we made a comprehensive transient stability analysis with three-phase temporary fault on each bus (excluding the generators' terminal buses) in advance. We found that the worst transient stability index (with the most negative value of $\eta$ ) corresponds to a three-phase fault condition occurred at Bus29. In this condition, the maximum angle separation happens between generator SG38 and generator SG39. Thus, in the following simulations, the generators SG38 and SG39 will be replaced by the wind farms equipped with GE 3.6MW [11] DFIGs with three-phase fault condition at Bus29 as benchmark to analyze the impacts of wind farm integration on the dynamic behavior of the test power system. We designed the following experimental scenarios: 1) In scenario 1, the synchronous generators SG38 and SG39 at Bus38 and Bus39 are equipped with exciters and power system stabilizers. The 4th order practical generator model is applied to the remaining synchronous generators. 2) In scenario 2, the synchronous generators SG38 at Bus38 is replaced by a wind farm DFIG38 with the same power output. The synchronous generator SG39 at Bus39 is equipped with exciters and power system stabilizers. The remaining synchronous generators are modeled as the 4th order practical model. 3) In scenario 3, the synchron-

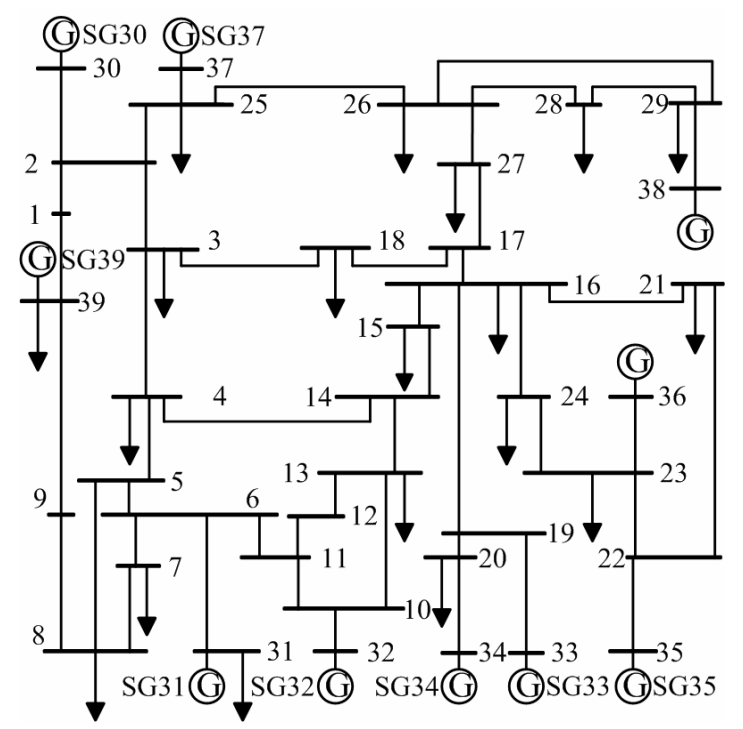

Figure 4. IEEE standard 10-generator-39-bus New England system 
ous generators SG38 and SG39 are replaced by wind farms DFIG38 and DFIG39 with the same power outputs, respectively. Similarly, the 4th order practical generator model is applied to the remaining synchronous generators. The corresponding experimental scenarios are summarized in Table $\mathbf{1}$.

As mentioned before, different load models involving the nonlinear load model and dynamic load model will be considered during the simulation comparisons. The applied load models are given in Table 2.

A three-phase temporary fault occurs at Bus29 at time $t=0.5 \mathrm{~s}$, and it is cleared at time $t=0.55 \mathrm{~s}$. The corresponding calculated transient stability indices considering different load models are given in Table $\mathbf{3}$ and Figures 5-6.

Table 1. Designed experimental scenario

\begin{tabular}{cc}
\hline Scenario & Synchronous Generators Replaced by Wind Farms \\
\hline 1 & N/A \\
2 & SG38 \\
3 & SG38 and SG39 \\
\hline
\end{tabular}

Table 2. Load model considerations

\begin{tabular}{cl}
\hline Load Model & \multicolumn{1}{c}{ Description } \\
\hline Z & $\begin{array}{l}\text { Constant impedance } \\
\text { ZIP }\end{array}$ \\
$\begin{array}{l}\text { Combination of } 30 \% \text { constant impedance (Z), 40\% } \\
\text { constant current (I) and 30\% constant power (P) }\end{array}$ \\
ZIP + Dyn & Combination of 30\% ZIP and 70\% induction motor \\
\hline
\end{tabular}

Table 3. Transient stability evaluation indices considering different load models

\begin{tabular}{|c|c|c|c|c|c|c|}
\hline Scenario & 1 & & & 2 & & 3 \\
\hline $\begin{array}{l}\text { Load } \\
\text { Model }\end{array}$ & $\eta$ & CCT(s) & $\eta$ & $C C T(\mathrm{~s})$ & $\eta$ & $C C T(\mathrm{~s})$ \\
\hline Z & 60.70 & 0.1379 & 66.60 & 0.5399 & 69.85 & 1.4712 \\
\hline ZIP & 59.58 & 0.1238 & 67.14 & 0.4402 & 70.17 & 0.9987 \\
\hline ZIP+Dyn & Insecure(-57.95) & 0.0421 & 67.58 & 0.0746 & 68.50 & 0.0676 \\
\hline
\end{tabular}

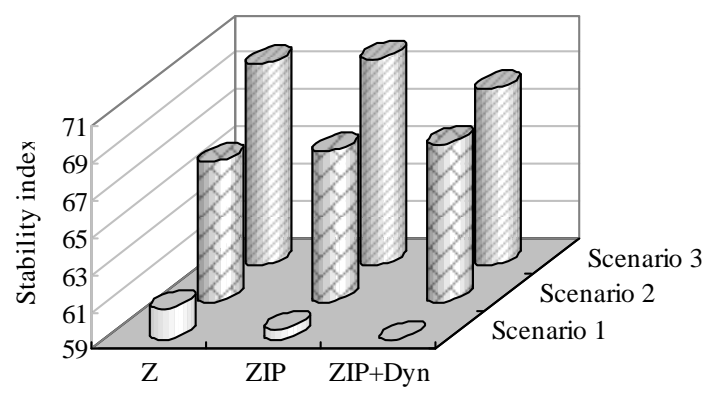

Figure 5. Power angle based stability indices with different scenarios and load models
From Table 3 and Figures 5-6, it can be seen that the system transient stability can be improved to some extent when the specific synchronous generator is replaced by a wind farm of DFIG type under current fault condition and with the consideration of different load models. It should be noticed that when considering the 'ZIP + Dyn' load models the power system consisting of all conventional synchronous generators (i.e. scenario 1) becomes unstable.

The maximum angle separation changes in different scenarios considering the 'ZIP + Dyn' load models. The corresponding maximum angle separations are given in Table 4.

From Table 4, it can be seen that the oscillation modes related to the transient stability index will change when some synchronous generators are replaced by wind farms of DFIG type.

Figures 7(a), 7(b), 7(c) and 7(d) show the active power output, rotor speed, reactive power output and terminal voltage curves of the wind farm DFIG38 and the replaced synchronous generator SG38 considering the 'ZIP + Dyn' load model, respectively. The solid line corresponds to the DFIG38 and the dotted line corresponds to the synchronous generator SG38. These figures show that the dynamic behavior of test system resulted in great changes after the introduction of wind farm of DFIG type. Under current condition, the synchronous generators cannot keep stable with great penetration of induction motor loads, which may lead to more reactive power requirements and more complicated oscillations. With the control strategies of DFIG converter and due to the soft connection between the mechanical and the electrical side of DFIG, the active and reactive power oscillations of DFIG during fault is relatively smooth, which is helpful for keeping the power system stable.

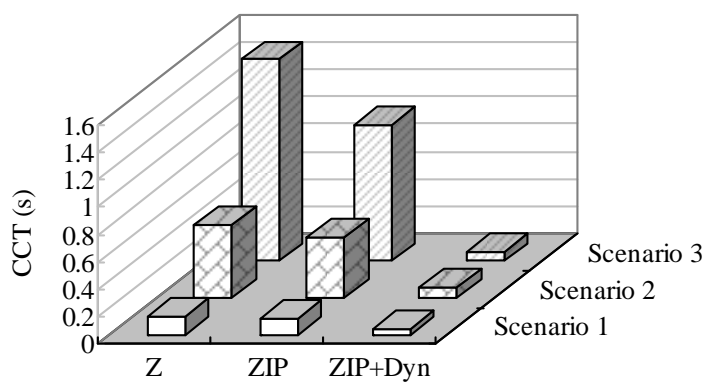

Figure 6. CCT with different scenarios and load models

Table 4. Maximum angle separations in different scenarios

\begin{tabular}{ccc}
\hline Scenario & Load Model & Maximum Angle Separation \\
\hline 1 & & $<\mathrm{SG} 34$, SG39> \\
2 & ZIP+Dyn & $<\mathrm{SG} 31, \mathrm{SG} 39>$ \\
3 & & $<\mathrm{SG} 30, \mathrm{SG} 31>$ \\
\hline
\end{tabular}


Similarly, Figures 8(a), 8(b), 8(c) and 8(d) give the active power output, rotor speed, reactive power output and terminal voltage curves of the wind farm DFIG39 and the replaced synchronous generator SG39 considering the 'ZIP + Dyn' load model, respectively. The dotted line corresponds to synchronous generator SG39 based on scenario 1; the dash-dot line corresponds to the synchronous generator SG39 based on scenario 2 and the solid line corresponds to the DFIG39 based on scenario 3.

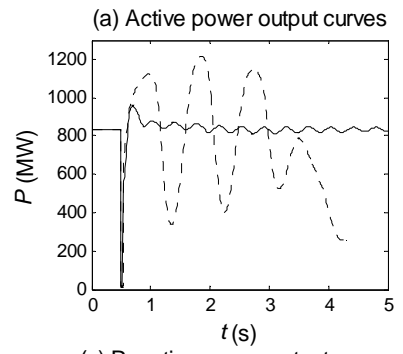

(c) Reactive power output curves

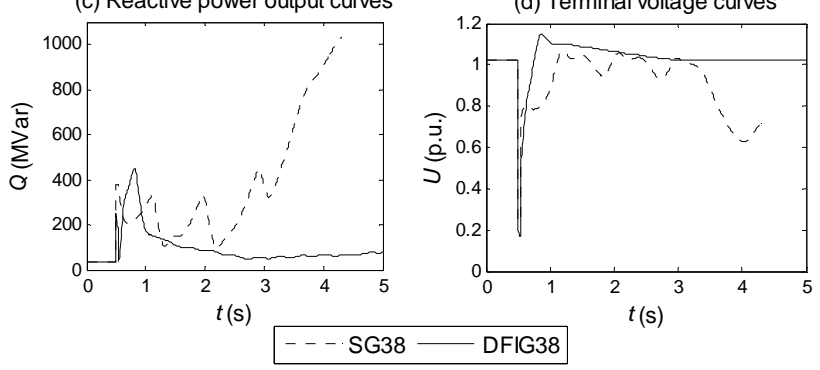

Figure 7. Transient behavior curves of the wind farm DFIG38 and the replaced synchronous generator SG38

(a) Active power output curves
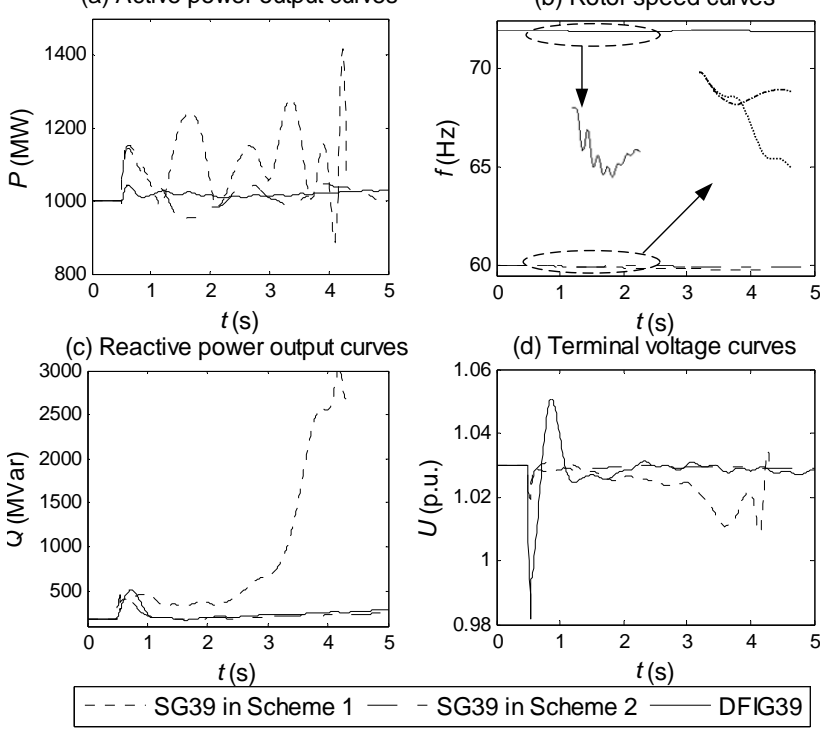

Figure 8. Transient behavior curves of the wind farm DFIG39 in scenario 3 and the replaced synchronous generator SG39 in scenario 1 and scenario 2
It can be seen from Figure 8 that wind farms of DFIG type replacing synchronous generators actually leads to great influence on the transient stability of the existing power system. Particularly, when the second wind farm DFIG39 is introduced into the test system, the transient stability of the test system is significantly improved.

\subsubsection{Wind Farms Connected to Existing Power Grid}

In our previous analysis of impact of grid-connected wind farm of DFIG type on transient stability, the wind farms are introduced into the power grid via replacing existing synchronous generators. Actually, it is unpractical to replace the existing synchronous generators with wind farms during application. When the wind farm is directly connected to the transmission system, the corresponding network topology and system operating condition will change. Therefore, it is necessary and imperative to explore and exploit the impact on the power system transient stability in this situation.

In following simulations, the wind farm equipped with GE 3.6MW DFIGs will be connected to each bus excluding ding generator buses to carry out the corresponding analysis. The synchronous generators are modeled as the $4^{\text {th }}$ order practical model. The load model which is a combination of $30 \%$ ZIP and $70 \%$ induction motor ('ZIP + Dyn') is considered as well. A three-phase temporary fault occurs at Bus29 at time $t=0.5 \mathrm{~s}$, and it is cleared at time $t=$ $0.55 \mathrm{~s}$. Consider that the load demands do not change before and after the integration of wind farm, the power outputs of each synchronous generator are decreased by 10 percent of wind farm rated capacity to meet load requirements. And in our studies, the wind farms at all grid connection points have to be able to operate at power factor between 0.975 lagging and 0.975 leading to provide reactive power. The corresponding calculated transient stability indices and maximum angle separations are given in Table 5.

From Table 5, it can be seen that when the wind farm is connected to most buses, the system transient stability can be increased under the specific fault condition with the consideration of the 'ZIP + Dyn' load models. Furthermore, the CCT is different with the different connection point of wind farm. The maximum CCT value is 0.0816 calculated at Bus26 with wind farm connected. The minimum CCT value is 0.0421 calculated at Bus1. Regarding the oscillation mode which may make the system transient stability unstable, we found that the maximum angle separation happens between synchronous generators SG38 and SG39 for almost all connection points of wind farm. When the wind farm is connected to bus20, the maximum angle separation is between SG34 and SG39.

Figures 9(a), 9(b), 9(c) and 9(d) show the active power output, rotor speed, reactive power output and terminal voltage curves of the wind farm of DFIG type connected to Bus 26 and Bus 1 considering the 'ZIP + Dyn' load model, respectively. The solid line corresponds to the 
Table 5. Transient stability indices and corresponding maximum angle separations

\begin{tabular}{|c|c|c|c|}
\hline \multirow{2}{*}{$\begin{array}{l}\text { Bus Number } \\
\text { Connected } \\
\text { Wind Farm }\end{array}$} & \multicolumn{2}{|c|}{ Transient Stability Indices } & \multirow{2}{*}{$\begin{array}{l}\text { Maximum Angle } \\
\text { Separation }\end{array}$} \\
\hline & $\eta$ & $C C T(\mathrm{~s})$ & \\
\hline 1 & Insecure(-58.32) & 0.0421 & $<$ SG38,SG39> \\
\hline 2 & 60.69 & 0.0676 & <SG38,SG39> \\
\hline 3 & 59.74 & 0.0676 & <SG38,SG39> \\
\hline 4 & 60.22 & 0.0605 & <SG38,SG39> \\
\hline 5 & 60.78 & 0.0605 & <SG38,SG39> \\
\hline 6 & 60.79 & 0.0605 & $<$ SG38,SG39> \\
\hline 7 & 61.06 & 0.0605 & <SG38,SG39> \\
\hline 8 & 61.21 & 0.0605 & <SG38,SG39> \\
\hline 9 & Insecure(-57.26) & 0.0474 & <SG38,SG39> \\
\hline 10 & 60.47 & 0.0605 & <SG38,SG39> \\
\hline 11 & 60.57 & 0.0605 & <SG38,SG39> \\
\hline 12 & 60.34 & 0.0535 & <SG38,SG39> \\
\hline 13 & 60.38 & 0.0605 & <SG38,SG39> \\
\hline 14 & 60.10 & 0.0605 & <SG38,SG39> \\
\hline 15 & 59.32 & 0.0605 & <SG38,SG39> \\
\hline 16 & 59.04 & 0.0676 & <SG38,SG39> \\
\hline 17 & 59.13 & 0.0676 & <SG38,SG39> \\
\hline 18 & 59.43 & 0.0676 & <SG38,SG39> \\
\hline 19 & 59.19 & 0.0605 & <SG38,SG39> \\
\hline 20 & 58.34 & 0.0605 & <SG34,SG39> \\
\hline 21 & 59.13 & 0.0605 & <SG38,SG39> \\
\hline 22 & 59.15 & 0.0605 & <SG38,SG39> \\
\hline 23 & 59.10 & 0.0605 & <SG38,SG39> \\
\hline 24 & 59.30 & 0.0676 & <SG38,SG39> \\
\hline 25 & 60.50 & 0.0746 & <SG38,SG39> \\
\hline 26 & 58.70 & 0.0816 & <SG38,SG39> \\
\hline 27 & 58.75 & 0.0746 & <SG38,SG39> \\
\hline 28 & 53.94 & 0.0676 & <SG38,SG39> \\
\hline $\begin{array}{l}\text { No wind farm } \\
\text { connected }\end{array}$ & Insecure(-78.30) & 0.0159 & <SG38,SG39> \\
\hline
\end{tabular}
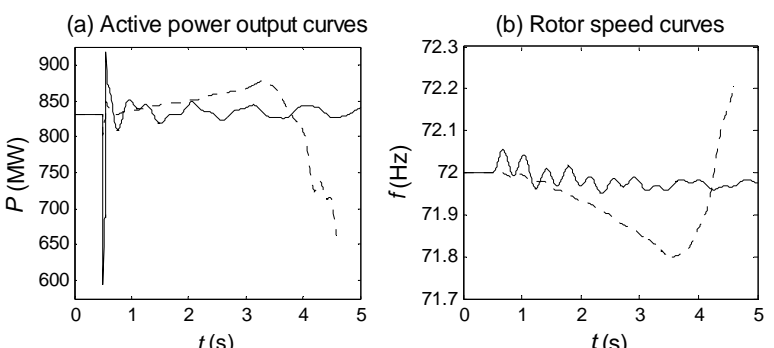

(c) Reactive power output curves

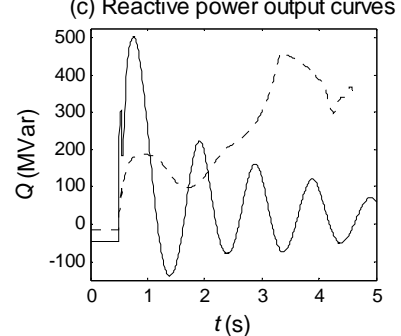

(d) Terminal voltage curves

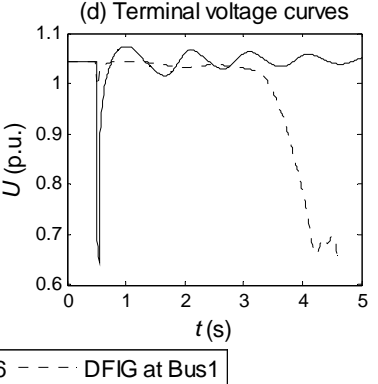

Figure 9. Transient behavior curves of the wind farms connected at Bus26 and Bus1 wind farm of DFIG type connected to Bus26 and the dotted line corresponds to the wind farm connected to Bus 1.

\section{Conclusions}

The transient stability simulation of power system with consideration of large-scale grid-connected wind farms of DFIG type are elaborately studied in this paper. The multiple wind farm integration with replacing synchronous generators is studied first. Furthermore, the impact on the power system transient stability with direct connection of wind farm of DFIG type is explored and exploited as well. According to the simulation results, some preliminary conclusions and comments are summarized and discussed. It should be pointed out that these conclusions and comments can provide useful information for power system planning and design when considering integrations of large wind farms with the existing power system. However, they are still preliminary and very limited. The impact of wind power on the transient stability of power systems involving the more actual factors needs to be elaborately studied further in the near future.

\section{REFERENCES}

[1] T. Ackermann, "Wind Power in Power Systems," Wiley, Chichester, 2005.

[2] E. Denny and M. O'Malley, "Wind Generation, Power System Operation, and Emissions Reduction," IEEE Transaction on Power Systems, Vol. 21, February 2006, pp. 341-347.

[3] M. S. Vicatos and J. A. Tegopoulos, "Transient State Analysis of a Doubly-Fed Induction Generator under Three Phase Short Circuit," IEEE Transaction on Energy Conversion, Vol. 6, March 2003, pp. 62-68.

[4] T. Senjyu, N. Sueyoshi, K. Uezato, H. Fujita and T. Funabashi, "Transient Stability Analysis of Induction Generator Using Torque-time Characteristic," The 5th International Conference on Power Electronics and Drive Systems, Vol. 1, Singapore, 2003, pp. 760-765.

[5] J. B. Ekanayake, L. Holdsworth, X. Wu and N. Jenkins, "Dynamic Modeling of Doubly Fed Induction Generator Wind Turbines," IEEE Transaction on Power Systems, Vol. 18, May 2003, pp. 803-809.

[6] L. B. Shi, Z. Xu, J. Hao and Y.X. Ni, "Modeling Analysis of Transient Stability Simulation with High Penetration of Grid-connected Wind Farms of DFIG Type," Wind Energy, Vol. 10, March 2007, pp. 303-320.

[7] S. M. Muyeen, H. A. Mohd, R. Takahashi, T. Tamura, Y. Tomaki, A. Sakahara and E. Sasano, "Transient Stability Analysis of Wind Generator System with the Consideration of Multi-mass Shaft Model," International Conference on Power Electronics and Drives Systems, Vol. 1, 2005, pp. 511-516.

[8] D. Gautam, V. Vittal and T. Harbour, "Impact of In- 
creased Penetration of DFIG-based Wind Turbine Generators on Transient and Small Signal Stability of Power Systems,” IEEE Transaction on Power Systems, Vol. 24, August 2009, pp. 1426-1434.

[9] B. Weise and M. Pöller, "Impact of High Wind Penetration on Transient and Oscillatory Stability Analysis," IEEE Power \& Energy Society General Meeting, Calgary, October 2009, pp. 16-22.

[10] L. B. Shi, S. Q. Dai, Y. X. Ni, Y. D. Zhao and M. Bazargan, "Transient Stability of Power System with High Penetration of DFIG based Wind Farms," IEEE Power \& Energy Society General Meeting, Calgary, October 2009, pp. 1-6.

[11] N. W. Miller, J. J. Sanchez-Gasca, W. W. Price and R. W. Delmerico, "Dynamic Modeling of GE 1.5 and 3.6 MW Wind Turbine-generators for Stability Simulations," IEEE Power Engineering Society General Meeting, Toronto, 2003, pp. 1977-1983.

[12] http://www.powertech.bc.ca; http://www.dsapowertools.com/

[13] Powertech Labs Inc. TSA user manual (version 6.0), Canada, April 2006.

[14] M. A. Pai, "Energy Function Analysis for Power System Stability,” Kluwer Academic Publishers, Boston, 1989. 